presentation of symptoms to a medical practitioner is recognised as part of the problem. This paper investigates response to symptoms of lung cancer in order to identify areas in which interventions have potential to increase early consultation.

Methods: Qualitative interviews were conducted with 42 people with lung cancer who had taken part in a quantitative interview survey. Interviews focused on symptoms and response prior to initial presentation and diagnosis. An integrated model of helpseeking behaviour was developed with reference to sociological and psychological theories to inform data analysis. Respondents who consulted within 12 weeks of symptom on-set were distinguished from those who did not and evidence of difference in their accounts sought.

Findings: Sociological and psychological models of response to symptoms are remarkably similar. "Domains" of response included the nature of symptoms, explanations for them, descriptions of action taken over time and prompting to respond from a family member. Respondents reported drawing on existing knowledge of symptoms, their likely cause and perceptions of personal risk. The nature of symptoms (acute, severe, chronic) was reported as influential as were family members who noticed symptoms. Causal theorising was ubiquitous and included explanations for symptoms in relation to cause and label; likely consequences; perceptions of control; consequences and how long it was likely to last. Actions included self-medication and "wait and see" strategies which were reassessed over time. People who consulted within 12 weeks of onset described symptoms that were largely acute and noticed by others but otherwise no differences were apparent. Smokers in particular reported unrealistic optimism of personal risk of lung cancer.

Conclusions: Models of illness behaviour from different social science disciplines can be integrated and used to frame understanding of reports of response to symptoms of lung cancer. Knowledge of symptoms is not wide-spread and symptoms attributable to benign causes unless acute or severe. Family members and other play an important role in prompting response. Interventions can target knowledge and the role of others in the context of theories of behaviour change.

\section{THE COST OF HAVING CANCER: A SURVEY OF PATIENTS WITH CANCER IN IRELAND}

${ }^{1} A$ Timmons, ${ }^{1} \mathrm{~L}$ Sharp, ${ }^{1} \mathrm{AE}$ Carsin, ${ }^{2} \mathrm{~N}$ Donnelly, ${ }^{2} \mathrm{~J}$ Kelly, ${ }^{2} \mathrm{~J}$ McCormack, ${ }^{2} \mathrm{~N}$ Chonghaile, ${ }^{3} \mathrm{E}$ O'Donnell, ${ }^{2} \mathrm{O}$ Ryan, ${ }^{1} \mathrm{H}$ Comber. ${ }^{1}$ National Cancer Registry Ireland, Building 6800, Cork Airport Business Park, Kinsale Road, Cork, Ireland; ' Irish Cancer Society, 43/45 Northumberland Road, Dublin 4, Ireland; ${ }^{3}$ St Vincent's University Hospital, Elm Park, Dublin 4, Ireland

\section{doi:10.1136/jech.2009.096719t}

Objectives: Although awareness is growing that a cancer diagnosis may have an adverse financial impact on some patients, few studies have been carried out to date. Although costs are likely to be multidimensional, most studies have investigated single dimensions, such as employment or travel costs. We aimed to: (1) quantify the proportion of patients incurring cancer-related additional expenditure or financial difficulties; (2) identify patient sub-groups at greatest risk of cancer-related additional expenditure/financial difficulties; and (3) assess monetary and psychosocial consequences of cancer-related additional expenditure.

Methods: The study setting was Ireland, which has a mixed publicprivate healthcare system. A postal questionnaire was developed from literature review and qualitative interviews with hospitalbased oncology social workers and cancer survivors. Questionnaire topics included: expenses incurred (e.g. hospital parking, prescriptions, GP visits, household utilities, etc.) and impact of cancer on income/benefits, meeting mortgage/loan payments, and household ability to make ends meet. The questionnaire also assessed levels of concern about household financial situation since diagnosis with cancer, and depression, stress and anxiety (using the DASS). Individuals with a primary breast, prostate, or lung cancer diagnosed within the previous 18 months were identified from the National Cancer Registry, Ireland and invited to complete the questionnaire during June-September 2008.

Results: 740 completed questionnaires were received (response rate $=54 \%$ ). Respondents had extra costs associated with travelling to hospital appointments (71\%), parking (52\%), GP visits $(36 \%)$, consultant visits (45\%), physiotherapy (9\%) and counselling (6\%). $59 \%$ reported increased household bills due to their cancer diagnosis. Meeting mortgage or loan payments was more difficult for $43 \%$ and $57 \%$ respectively. $30 \%$ of respondents reported decreased income. The consequences of additional expenses included: using savings (55\% used some or all of their savings); borrowing money (11\%); reduced spending on "extras" such as take-away meals $(21 \%)$. One third was more concerned about their household's financial situation; this did not vary by sociodemographic factors. For $44 \%$ of patients the cancer diagnosis had made it more difficult for their household to make ends meet. This percentage was higher amongst patients who were younger, of working age, or had dependents. Those who reported more difficulty in making ends meet were significantly more likely to be depressed, stressed or anxious $(p<0.01)$.

Conclusions: Most patients/families incur cancer-related additional costs. For some, these costs are substantial. The consequences of this additional expenditure are wide-ranging. These findings have important implications for patient support organisations, health and social services and policy makers.

\section{MORTALITY AND CANCER MORBIDITY IN A COHORT OF BRITISH MILITARY VETERANS INCLUDED IN CHEMICAL WARFARE AGENT EXPERIMENTS AT PORTON DOWN}

${ }^{1} \mathrm{LM}$ Carpenter, ${ }^{1} \mathrm{KM}$ Venables, ' $\mathrm{L}$ Linsell, ${ }^{1} \mathrm{C}$ Brooks, ${ }^{1} \mathrm{TJ}$ Keegan, ${ }^{1} \mathrm{~T}$ Langdon, ${ }^{2} \mathrm{P}$ Doyle, ${ }^{2} \mathrm{NES}$ Maconochie, ${ }^{3} \mathrm{~T}$ Fletcher, ${ }^{4} \mathrm{MJ}$ Nieuwenhuijsen, ${ }^{5} \mathrm{~V}$ Beral. ${ }^{1}$ Department of Public Health, University of Oxford, Oxford, UK: ${ }^{2}$ Department of Epidemiology and Population Health, London School of Hygiene and Tropical Medicine, London, UK; ${ }^{3}$ Department of Public Health and Policy, London School of Hygiene and Tropical Medicine, London, UK; ${ }^{4}$ Division of Epidemiology, Public Health and Primary Care, Imperial College, London, UK; ${ }^{5}$ Cancer Epidemiology Unit, University of Oxford, Oxford, UK

doi:10.1136/jech.2009.096719u

Objective: To study whether there may be long-term effects on the mortality and cancer morbidity of participants in experimental research related to chemical warfare agents conducted at the UK research facility at Porton Down

Design: Historical cohort study.

Setting and Participants: 18276 male members of the UK armed forces who spent one or more short periods at Porton Down between 1941 and 1989 and a comparison group of 17600 nonPorton Down veterans followed to 31 December, 2004. All veterans were considered for the cancer analyses, excluding those known to have died or been lost to follow-up before 1 January 1971: 17013 Porton Down and 16520 non-Porton Down veterans.

Main Outcome Measures: Mortality and cancer rates in Porton Down veterans were compared to those of non-Porton Down veterans and the general population, adjusted for age and calendar period.

Results: Porton Down and non-Porton Down veterans were similar in military and demographic characteristics. Year of enlistment was the same (median $=1951$ ) but the Porton Down veterans had longer military service (median $=6.2$ vs 5.0 years). After a median follow-up of 43 years, 7306 and 6900 respectively had died. All-cause mortality was slightly greater in Porton Down veterans (RR 1.06, 95\% CI 1.03 to $1.10, p<0.001$ ), more so for deaths outside the UK $(1.26,1.09$ to 1.46). Of 12 cause-specific groups examined, RRs were increased for deaths attributed to 